\title{
Teatro Negro proposto pela Cia. Espaço Preto ou a formação de
}

\section{um ator-pesquisador-docente negro}

\author{
The Black Theater proposed by Cia. Espaço Preto or the formation of a black actor- \\ researcher-teacher \\ Anderson Ferreira do Nascimento \\ Licenciado em Teatro pela Universidade Federal de Minas Gerais (UFMG) - andersonf.n@hotmail.com
}

\begin{abstract}
Resumo
$O$ presente artigo sugere uma reflexão sobre a criação da companhia teatral Espaço Preto, de Belo Horizonte, Minas Gerais, observando nas suas propostas artísticas alguns tópicos das discussões sobre a poética do Teatro Negro e da Arte Marginal. Objetiva-se ainda ampliar possibilidades em relação aos temas e as formas na produção dessa linguagem, bem como a formação sociopolítica do(s) individuo(s) negro(s) que a compõem. Para isso, foram analisados os processos de concepção dos espetáculos "O grito do outro - o grito meu!" e "Ama", os ensaios do grupo para as apresentações, os bate-papos com o público e as reverberações nos bastidores. A abordagem estética incorporada nos trabalhos da companhia atravessa o limite criado para se tratar da história e da vivência do negro no Brasil, por vezes relacionadas somente a religiosidade. Estabelece-se, portanto, uma referência periférica e urbana para tratar cenicamente das questões do racismo e de discussões mais específicas relacionadas à mulher negra e ao genocídio de jovens negros.
\end{abstract}

Palavras-chave: Teatro Negro. Espaço Preto. Formação teatral.

\begin{abstract}
This article proposes a reflection on the creation of Espaço Preto, the theater company from Belo Horizonte, Minas Gerais, observing some topics about the poetics of the Black Theater and marginal art and its discussions. Yet, it aims to wide possibilities about the subjects and the forms in this language production, as well as the sociopolitical training of the black individuals whom are part of the Company. The design process of the shows "O grito do outro - o grito meu!" and "Ama", the assay sections, the chats with the public and the reverbarations behind the scenes were analyzed for the previous goals. The aesthetic approach in the works of the company crosses the bonds created to treat History and the black life experience in Brazil, many times attached to religiosity. It establishes, therefore, a peripheral and urban reference to deal with the issues of racism and more specific discussions related to black women and the genocide of young blacks.

Keywords: Black Theatre. Espaço Preto. Formation.
\end{abstract}

Recebido em: 03/04/2018

Aceito em: 11/06/2018 
É necessário reconhecer o teatro negro contemporâneo como aquele que constrói uma poética própria, resultado do que rodeia sua identidade: afetos, realidade social, imaginário, ancestralidade, resistência ou qualquer outra forma que reflita sua identidade. (Grace Passô ${ }^{1}$ )

\section{INTRODUÇÃO}

É inevitável conter a intervenção das lembranças. Memórias que me fazem refletir sobre nossa chegada até aqui: são histórias que se cruzam, lutas que se complementam e corpos em constante resistência e movimento. Miramos a Cia. Espaço Preto! Companhia teatral que se dedica à pesquisa de Teatro Negro e arte marginal, na qual, além de membro-fundador, sou ator, pesquisador e figurinista. Nesta escrita, pretendo me debruçar sobre o momento da criação da Cia Espaço Preto, explorando nos primeiros anos da sua trajetória, a formação de um ator-pesquisadordocente dentro de uma companhia de teatro. Observo e reflito o amadurecimento político do indivíduo/grupo e as possibilidades do Teatro Negro.

A Cia. Espaço Preto é um agrupamento de artistas negros e negras, oriundos das artes visuais, da dança e do teatro, que possui, em seus trabalhos, elementos da cultura negra para pensar a condição do negro no Brasil, as relações étnico-raciais e o racismo. Atualmente, seu repertório conta com os espetáculos O grito do outro - O grito meu! (2016), Ama (2017) e a cena curta Mãe da Rua (2017), que também é uma proposta de espetáculo.

\section{A CRIAÇÃO DA CIA ESPAÇO PRETO: RESISTÊNCIA, LINGUAGEM E POÉTICA}

A companhia Espaço Preto surgiu no contexto universitário do curso de graduação em Teatro da Universidade Federal de Minas Gerais (UFMG) a partir de uma lacuna em que havia (há) uma rara ou quase nenhuma apresentação de temas afro-brasileiros no currículo. Por essa razão,

\footnotetext{
${ }^{1}$ Atriz e dramaturga, negra. Citação retirada do programa da IV Mostra Benjamin de Oliveira (2016), em Belo Horizonte/MG.
} 
em 2012, Adélia Carvalho, negra², na posição de professora substituta, ofereceu uma disciplina optativa sobre Teatro Negro. Pedro Amparo, aluno, negro, matriculado na disciplina vendo-se diante das referências e das discussões trazidas pela professora, decidiu reunir-se com outros discentes negros e negras do curso para ajudá-lo a produzir seu Trabalho de Conclusão de Curso sobre a temática afro-brasileira. Éramos no elenco: Ana Martins, Anair Patrícia, Andréa Rodrigues, Guilherme Diniz, Helen Salgado, Lúnia Martins, Michele Bernardino, Pedro Amparo, Rainy Campos e Sitaram Custódio e eu. Também na equipe havia alunos de outros cursos como Guilherme Pires, do Designer de Moda, que assinou o figurino do espetáculo, Antonio Salgado, Del Lopes, Marcelo Padovani e Thais Gallo, das Artes Visuais, responsáveis pela parte cenográfica e visual do espetáculo. Arthur Arock, branco, já formado pelo curso, auxiliava o Pedro na dramaturgia e Cezar Frank, negro, também formado pelo curso, cuidava de toda iluminação cênica.

Quando Pedro me chamou para integrar o trabalho, houve um choque de minha parte. Eu que já me reconhecia negro, não conhecia o lugar político ocupado por essa questão. Já era sabido que eu não possuía o mesmo registro que um negro retinto ${ }^{3}$, mas esse convite foi reverberando em mim no princípio como medo das consequências e depois em uma constante busca do que isso queria dizer. Foi nos encontros, processo de montagem do espetáculo/TCC, que compartilhando e ouvindo as vivências dos colegas de equipe, negros e negras, pude perceber um cotidiano parecido com o meu. Mesmo sendo pessoas negras vindas de diversos lugares, alguns de São Paulo, outros de Belo Horizonte, região metropolitana ou do interior de Minas Gerais, nossas histórias se cruzavam em algum momento da infância, da escola básica, da família. Eram/são realidades semelhantes de pessoas periféricas que conviviam/convivem com a discriminação e o preconceito diariamente. Dessas narrativas surgiu o fio condutor do espetáculo, em articulação com o tema do artigo do Pedro sobre Arte Marginal e Dramaturgia Negra, no momento em que assumimos esse lugar de fala e de dramaturgos do próprio drama.

\footnotetext{
${ }^{2}$ No decorrer desse texto, classifico e exponho a identidade étnico-racial das pessoas que compõem as histórias para fazer articulação com seus respectivos discursos e, principalmente, como afirmação das pessoas negras. Os princípios classificatórios que atravessam essa pesquisa estão baseados no fenótipo, nas relações culturais e nos processos de identificações.

${ }^{3}$ Negro de pele mais escura.
} 
Naquele momento inicial, na sala de ensaio, quase não sabíamos por onde ir. O professor Marcos Alexandre ${ }^{4}$, negro, orientava o Pedro no artigo (e, logo depois, tornou-se parceiro do grupo), mas nós éramos responsáveis pela criação do espetáculo. Era hora de propor tudo o que a universidade nos negou. Compartilhamos textos, músicas, poesias, mitos, imagens (fotografia, pintura, escultura etc.) de outros artistas negros. Era uma espécie de alfabetização na literatura/arte/teatro negro. Um mundo novo, mas que havia representatividade. Existiam pessoas que dialogavam, já há algum tempo, com o que desejávamos expressar. Não estávamos sozinhos, só não sabíamos da existência delas. Pude aprender bastante, principalmente com alguns elementos da arte marginal (marginalizadas) que eu mesmo julgava de forma negativa ao reproduzir um racismo coletivo, como o rap, o grafite e o pixo, pois essas práticas artísticas eram proibidas na minha casa por possuir, segundo minha família, uma relação negativa com o crime, as drogas e a violência.

Esses elementos sustentavam nossas pesquisas em companhia dos textos de Leda Martins e Marcos Alexandre, que nos apresentaram, por meio de suas escritas, o Teatro Experimental do Negro (TEN). O TEN foi o grupo de Teatro Negro criado por Abdias Nascimento ${ }^{5}$ em 1944 a fim de contribuir com a discussão sobre a democracia racial, questionando a representação do negro na dramaturgia universal, na qual era posto em cena por meio de papéis secundários ora escravizado, ora exaltado por estereótipos cômicos. O TEN buscava inserir o negro no espaço teatral dando-lhe reconhecimento de sua cultura e seu protagonismo na constituição da historiografia brasileira. (ALEXANDRE, 2017, p. 31).

Convencidos por esses propósitos, em novembro de 2014, estreamos "Primeiramente Negra", na sede do teatro Espanca!, centro de Belo Horizonte -MG. O primeiro Trabalho de

\footnotetext{
${ }^{4}$ Professor da Faculdade de Letras (FaLe/UFMG), também leciona disciplinas ofertadas para o curso de Teatro. 0 segundo professor negro que eu tive contato durante o curso: no TCC do Pedro Amparo e no projeto de extensão "Literatura Afro-brasileira em Foco".

${ }^{5}$ Escritor, artista plástico, teatrólogo, político e poeta, Abdias Nascimento foi um dos maiores ativistas pelos direitos humanos e deixou um legado de lutas pelo povo afrodescendente no Brasil. Participou da Frente Negra Brasileira nos anos 1930 e ajudou a organizar o Congresso Afro-Campineiro em 1938. Criou na Penitenciária de Carandiru, em 1941, o Teatro do Sentenciado. Ao sair da penitenciária, fundou no Rio de Janeiro, em 1944, o Teatro Experimental do Negro.

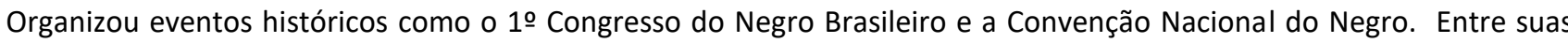
obras mais expressivas estão Axés do Sangue a da Esperança (orikis); Sortilégio (Mistério Negro); Drama para Negros e Prólogo para Brancos (antologia do teatro negro brasileiro); $O$ genocídio do negro brasileiro e $O$ Quilombismo (INSTITUTO DE PESQUISAS E ESTUDOS AFRO BRASILEIROS, [201-] década certa).
} 
Conclusão de Curso da graduação em Teatro da UFMG com uma equipe formada majoritariamente por negros e negras estreava, setenta anos depois da fundação do TEN. Assim, corroboramos as palavras de Christian Moura, negro, que, presente no dia da estreia, deixou-se afetar pela apresentação:

\begin{abstract}
As dramaturgias sonora e visual inicial da cena confundem-se com o barulho dos carros na rua e a fala dos operários: "SAI CAPETA! QUEIMA ELE!" e com as escrituras dos muros localizados nos arredores do Viaduto Santa Tereza. Num ato performático um jovem negro ascende velas num altar político. Já na caixa preta o som do mar e o rapper Sabotage abrem o drama, se é que ainda temos personagens em drama? Embora as perguntas para responder se é possível nos dias atuais a formalização de um teatro sem personagens e sem drama, que apresentem um senso crítico frente "aos discursos dominantes, tais quais os andro- (falo-), hetero-, euro e etnocentrismo", já tenham sido dadas no programa da peça: “De onde vieram os negros? Onde estão os negros? Quem é negro?" (MOURA, 2014, p. 2).
\end{abstract}

Logo depois da apresentação e de uma repercussão para além dos muros da universidade, consideramos que o trabalho estava apenas começado e que seria importante firmar nosso pensamento político enquanto artistas negros, dos quais a presença no palco transcendia o viés interpretativo. Leda Maria Martins, em a Cena em Sombras (1995), disserta o mesmo fato sobre o TEN, quando "desde sua formação, o TEN apresentava-se como um projeto cultural de intenções mais abrangentes, que não se restringiam apenas à área da representação teatral, definindo-se assim como 'um amplo movimento de educação, arte e cultura'” (MARTINS, 1995, p. 78).

Aos poucos fomos construindo nossa poética, observando, compreendendo e fundamentando sobre o espetáculo criado e o teatro que estávamos propondo.

À vista disso, Marcos Antônio Alexandre, no seu livro $O$ teatro negro em perspectiva: dramaturgia e cena negra no Brasil e em Cuba (2017), ao citar e compartilhar com Evani Tavares de Lima, a partir da tese Um olhar sobre o Teatro Experimental do Negro e do Bando de Teatro Olodum, nos direciona para a perspectiva do que é Teatro Negro, bem como o dividindo em três categorias. Sendo:

aquele que abrange o conjunto de manifestações espetaculares negras, originadas da Diáspora, e que lança mão do repertório cultural e estético de matriz africana como meio de expressão, de recuperação, resistência e/ou afirmação da cultura negra. Este teatro negro pode ser classificado em três grandes categorias: uma primeira que, genericamente, denominaremos performance negra, abarca formas de expressivas, de modo geral, e não prescinde de audiência para acontecer; a segunda, categoria (também circunstancialmente 
definida), teatro de presença negra estaria relacionada às expressões literalmente artísticas (feitas para serem vistas por um público) de expressão negra ou com sua participação; e a terceira categoria, teatro engajado negro, diz respeito a um teatro de militância, de postura assumidamente política (LIMA apud ALEXANDRE, 2017, p. 34-35).

Lima, com base na categoria teatro engajado negro, manifesta o que estávamos propondo com a Cia. Espaço Preto: "uma discussão de questões referentes à situação do negro na sociedade e à defesa de sua identidade e cultura" (LIMA apud ALEXANDRE, 2017, p. 35). Sobre a categoria performance negra, que abarca algumas expressões religiosas como o congado, o samba rural, tambor de mina etc., decidimos, após várias discussões, que não iríamos aprofundar nessa questão, pois, além de não serem todos os integrantes adeptos a uma religião de matriz africana, é entendido, hoje, que podemos dialogar

\begin{abstract}
com outras nuances que exploram características relacionadas com aspectos políticos e ideológicos que possam assumir espaços voltados para questões dos afetos e das subjetividades, demonstrando que há um vasto campo de atuação do teatro negro e que este, hoje, não mais se restringe exclusivamente ao caráter da religiosidade. Ainda que esse tema seja de suma importância [...] é apenas uma entre as muitas possibilidades de composição dramatúrgica e estética do teatro negro (ALEXANDRE, 2017, p. 36).
\end{abstract}

Essas expressões são e serão sempre respeitadas na companhia, mas é de interesse do grupo pesquisar como esses corpos negros se constituem na contemporaneidade periférica/urbana. Concepção estética que logo se deu na prática: quando na construção do nosso segundo espetáculo $O$ grito do outro - o grito meu! (2015) tivemos a preparação corporal a partir de elementos do hip-hop. As oficinas foram guiadas por Elisa Nunes, membro da companhia, atriz e dançarina, negra, que nos revelou alguns passos das "batalhas de passinho" nos guetos brasileiros e dos EUA. Nesse momento, o ritmo permanecia nos corpos negros, porém se estabelecendo "por outras instâncias corpóreas" conectadas com as batidas em que os tambores davam/dão lugar aos beats $^{6}$ (ALEXANDRE, 2017, p. 114).

Diante dessas escolhas, os encontros começaram a ser encaminhados segundo um foco específico, já possuindo referências próprias, diálogos e temas de interesse. Iniciamos com o treinamento corporal guiado pela Elisa e, em dias alternados, passamos pelo trabalho vocal trazido pela Rainy Campos, sempre seguido de improvisações em grupo. Por fim, uma discussão de um

\footnotetext{
${ }^{6}$ Base musical presente no ritmo do funk e do rap.
} 
tema alicerçado em algumas leituras, para construção de ideias e dramaturgia. Nesse segundo trabalho, O grito do outro - O grito meu!, optamos por uma direção/processo colaborativo e convidamos o Marcos Alexandre para nos orientar na dramaturgia.

\title{
3 A IMPORTÂNCIA DA CIA ESPAÇO PRETO NA FORMAÇÃO DE UM ATOR-PESQUISADOR-DOCENTE NEGRO
}

A partir dessa configuração de encontro/ensaio, é ainda mais notória a importante participação da Cia. na minha formação como ator, mas que também pretende exercer a docência na área de teatro e anseia levar para o ambiente escolar as propostas da Lei 10.639/037. Assim, além de fortalecer meu senso político-social, a Espaço Preto me proporciona "experiências formativas" fora da academia, que me fazem lidar melhor com o cotidiano, com os saberes e a coletividade. Tal como sugere Olga Rodrigues de Moraes Simson (2007, p. 14), ao trazer as discussões acerca da educação não formal:

\begin{abstract}
a busca por práticas mais significativas e condizentes com os desejos, necessidades e vontades de um público [...] que se relaciona e interage. E que, desse modo, os processos de formação profissional sejam mais ricos de sentidos e possibilidades, fazendo com que os educadores sintam-se, de fato, autores de um projeto educacional coletivo. Que vejam e sintam-se incluídos, participantes e atuantes de forma efetiva, reflexiva, consciente e política nas possíveis mudanças e transformações do social que venham a promover e ocorrer.
\end{abstract}

Para mais, de acordo com Simson (2007, p. 37), em "Educação não-formal: um conceito em movimento":

\begin{abstract}
É importante observar que a educação não-formal exige uma atitude política do educador perante a realidade, pois, ao abrir novas perspectivas de ação, permite negar um certo determinismo que a visão histórica de longa duração possa sugerir. Ela pressupõe a constatação de que os grupos dominados não são passivos, mas sim capazes de engendrar reações aos processos de dominação, criando espaços de "resistência inteligente".
\end{abstract}

Os espaços criados pela companhia me instigaram a realizar alguns experimentos particulares que posteriormente foram levados à universidade e a partir do retorno dado tornaram-

\footnotetext{
${ }^{7}$ Uma política de reparação e de reconhecimento, conquistada pelo Movimento Negro, que torna obrigatório, em toda rede de Educação, o ensino sobre a História da África e dos Africanos, destacando e reconhecendo a luta dos negros no Brasil, a cultura negra brasileira e o negro na formação da sociedade nacional.
} 
se projetos abraçados pela Espaço Preto. Um desses projetos foi a cena curta "Ama"8, que atualmente se configura como o terceiro espetáculo da companhia (e sobre o qual desdobro uma reflexão mais ampla no tópico adiante). Esse trabalho fora iniciado no final de 2015 em parceria com Anair Patrícia, no qual recorremos às vivências e memórias das nossas matriarcas (mães e avós) para dar corpo e voz à Ama e à Jinga/Medéa. A cena é livremente inspirada no texto dramatúrgico "Além do rio"9, de Agostinho Olavo, escrito em 1957 (uma releitura da tragédia "Medéa", de Eurípides) e denuncia a arraigada "Ideologia do Branqueamento"10, que determina como padrão estético e norma comportamental, os referenciais marcados pelo signo da brancura, opondo-os aos modelos negros, pretendendo abrir questionamentos sobre a solidão da mulher negra e a violência cometida contra elas, como também o genocídio de jovens negros. Depois de apresentar esse experimento em alguns eventos universitários, lançamos a cena como produção da companhia em setembro de 2016, no 17ㅇ festival de cenas curtas do Galpão Cine Horto.

Outra experiência formativa na Cia Espaço Preto são os bate-papos depois das apresentações do espetáculo ou das cenas curtas. Realizamos essas rodas de conversas, sempre que possível, para abrir o diálogo com o público e compartilhar questões, impressões e inquietações, acontecendo algumas vezes na programação de festivais e quando apresentamos de forma autônoma.

Uma dessas ações de desdobramentos do espetáculo se deu no Teatro Marília, em Belo Horizonte/MG, quando apresentamos 0 grito do outro - o grito meu!, no dia 28 de agosto de 2016, às $19 \mathrm{~h}$, por meio de um edital de ocupação dos teatros públicos da cidade. O bate-papo foi mediado por Lira Ribas a convite da companhia com o seguinte roteiro: apresentação do grupo, exposição de alguns elementos do processo de criação e perguntas vindas do público. Logo na primeira pergunta, um homem de mais idade, branco, nos questionou sobre a existência do teatro negro e desejava saber se era racismo caso alguém criasse um "teatro branco". Outra mulher, branca, se dizia representada em cena, pois tinha "um pé" na negritude por seu avô ser negro,

\footnotetext{
${ }^{8}$ Foto 3 em anexos.

9 Publicado unicamente na antologia de teatro negro brasileiro Dramas para negros e prólogo para brancos (NASCIMENTO, 1961).

10 "uma estrutura adotada no Brasil, após a abolição, que pretendia a reformulação étnica da população, associada ao pensamento de garantia do progresso e desenvolvimento da nação. Nessa política, encontra-se a ideia de que a miscigenação levaria o Brasil do futuro a assistir ao surgimento de um novo tipo racial que, logicamente, não estaria próximo ao negro, mas um tipo híbrido, mais aproximado do europeu". (GOMES, 1995, p.82)
} 
lamentou a "ausência de melanina" e completou dizendo que isso não excluía suas dores, pois, a exemplo da Escrava Isaura ${ }^{11}$ havia sofrimento por parte dos brancos. Uma mulher negra de meia idade relatou que parecia estar assistindo sua vida no teatro. Sua família, as opressões diárias etc. e ficava "indignada" por uma pessoa branca querer comparar as opressões, "depois de uma peça dessa", disse ela. Algumas dessas perguntas e relatos foram respondidas e comentadas por pessoas negras e não negras da plateia. Quase sempre isso acontece e a proposta do dialogo se constrói. Só intervimos quando saem do contexto ou iniciam uma confusão. Ou seja, a Cia. traz para a cena um material cênico e latente para a discussão do tema e, na sequência, media a conversa, sem impor ou intimidar seu posicionamento político-estético.

Sobre a criação de um "teatro branco", Andréa Rodrigues Silva, membro fundadora e atriz da Cia., respondeu da seguinte forma:

\begin{abstract}
Não precisa criar um teatro branco. Ele já existe, está aí. O teatro é branco. Os papéis na maioria das peças são para pessoas brancas. A chance de um branco conseguir um papel já existe. Eu precisei esperar que viesse o "negro" na rubrica para conseguir atuar. Por isso que a ideia de um coletivo negro incomoda. Mas não incomoda a ausência de negros nas montagens (SILVA, 2016).
\end{abstract}

Fomos contemplados pela fala da Andréa, mesmo que depois, com a poeira baixa, pensei que ainda assim, com o "negro/negra" na rubrica, tínhamos situações de blackface até o presente. O espectador que fez a pergunta a parabenizou pela resposta e pelo trabalho. Ele não foi o primeiro. Acreditamos que demais espectadores já questionaram dessa forma vários grupos de teatro negro. Andréa ainda narrou no camarim que uma companheira do curso, branca, havia sugerido que ela não reclamasse mais, pois tínhamos o $\mathrm{FAN}^{12}$ e que ela por ser branca não participava. Depois, começamos a perceber várias outras formas de segregação no cenário teatral de Belo Horizonte, onde as peças com temáticas afro-brasileiras eram/são apresentadas dentro de uma programação específica a partir de datas como 13 de maio e 20 de novembro e excluídas da programação "normal" durante o ano.

Mais uma situação de bate-papo se deu no 17ํㅜ Festival de Cenas Curtas do Galpão Cine Horto, porém com a cena "Ama". Apresentamos no dia 15 de setembro de $2016^{13}$, às $21 \mathrm{~h}$, e o batepapo aconteceu no dia seguinte às $19 \mathrm{~h}$ guiado pela jornalista convidada Joyce Athiê e por Marcos Coletta. Estavam na ocasião os artistas das outras três cenas apresentadas na noite anterior e eu,

\footnotetext{
${ }^{11}$ Uma escravizada branca, personagem da obra de Bernardo Guimarães, publicada em 1875.

${ }^{12}$ Festival de Arte Negra realizado a cada dois anos em Belo Horizonte/MG.

${ }^{13}$ Foto em anexo.
} 
Anair Patrícia e Andréa Rodrigues- representantes da Espaço Preto, além do público. Seguimos o mesmo roteiro: falamos um pouco do processo e depois abrimos para as perguntas. Vale a pena ressaltar que mais cedo a Joice Athiê lançou uma crítica sobre nossa apresentação, aproveitando o "calor da cena". Discorreu ela:

(...) Em seguida veio "Ama", também ocupando o lugar do protagonismo, da valorização da identidade negra e de um olhar para o periférico. A cena parecia ter saído de um programa popular de humor de televisão, mas daqueles roteirizados com inteligência. Levou Medeia para o morro, compondo um diálogo entre a tragédia grega e os modos e costumes despojados, mais libertos e sem papas na língua, de uma bicha da periferia. 0 empoderamento do homem-negro-homossexual-não-heteronormatizado da periferia constrói um cabeleireiro, consciente de suas questões, centrado em cada valor de sua cultura e da sua identidade, e que carrega no corpo a alegria como fator de resistência.

No morro, a cena revela todo modo de resistência pela permanência de uma cultura que se desenvolve no Brasil, tomando características específicas, mas que tem suas origens nas matrizes africanas. A religião, a identidade, o modo de usar o cabelo, a música e uma série de referências linguísticas e culturais são postas em cena.

$O$ interessante é que o trabalho trata do encontro e do embate de dois mundos - o morro e a elite, o preto e o branco, sem deixar de traçar os elos e os canais de comunicação e afetação, sem perder de vista os embates e os enfrentamentos dos diferentes.

Também me interessa ver a mudança que ocorre na personagem Jinga/Medeia. Aparentemente, colonizada no encontro com o mundo branco, ela retorna ao seu lugar de origem negando uma série de valores, hábitos, estéticas, crenças e gostos. O retorno à periferia, mesmo que em uma simples passagem pelo cabeleireiro amigo, parece ser como um respiro de energias e lembranças daquilo que se é e que não precisa ser mudando ou transformado por padrões colonizadores. Entre Jinga e Medeia, roda uma gira que lembra a mulher de suas raízes e seus poderes. Em tempos de boicote à umbanda e ao candomblé como representantes das crenças de matriz africana no centro ecumênico dos Jogos Olímpicos, falar de religião é uma pertinência (ATHIÊ, 2016).

Com esta participação, acreditamos ser uma das nossas primeiras aparições para a elite branca do teatro mineiro, público fiel e majoritário nesse festival. A apresentação estava em processo de reverberação tanto nos nossos corpos quanto nos corpos deles. Então, as primeiras perguntas eram permeadas de "parabéns" e também relacionadas com a formação do grupo. Reforçaram um ponto da reflexão publicada pela Joice, referente à situação do centro ecumênico dos Jogos Olímpicos e aproveitaram para perguntar sobre o texto que nos inspirou, pois essa Medeia era "desconhecida".

Percebemos diante desses dois momentos de diálogo com o público, o quanto o teatro negro ainda precisa ser didático e panfletário ${ }^{14}$.Não julgo aqui a capacidade intelectual do espectador tampouco a qualidade artística do teatro em questão, mas é evidente que, para algumas pessoas (negras principalmente), os signos e as referências são identificados com rapidez

\footnotetext{
14"É didático todo teatro que visa instruir seu público, convidando-o a refletir sobre um problema, a entender uma situação ou adotar uma certa atitude moral ou política" (PAVIS, 2011, p. 386).
} 
e para os não negros, os temas são territórios desconhecidos, ora pela histórica tentativa de silenciamento e apagamento dessas memórias, ora por negligência. E existe essa preocupação quando construímos um trabalho. Por isso, quando alguém pergunta se determinada cena tem relação com determinado fato, respondemos "sim, também". Pois em um país onde o racismo não dá sossego, não nos falta material. A construção dramatúrgica é quase que diária.

\title{
4 O ESPETÁCULO AMA
}

Ama (2017), que também foi meu espetáculo de formatura no curso de bacharelado em Interpretação Teatral da UFMG ${ }^{15}$, segue esse ritmo de construção. A montagem, como já dito, se apropria do texto Além do rio, de Agostinho Olavo, que

\begin{abstract}
conta a história de uma rainha africana escravizada e trazida para o Brasil do século XVII. Feita amante do senhor branco, ela trai sua gente, é desprezada pelos ex-súditos escravizados. Chega o dia do amante querer um lar, um casamento normal com uma esposa branca, de posição social. Rompe sua ligação com Medéa, mas quer levar os filhos. A rainha mata seus próprios filhos, no rio, e retorna a seu povo, convocando: "- Vozes, ó vozes da raça, ó minhas vozes, onde estão? Por que se calam agora? A negra largou o branco. Medéa cospe este nome e Jinga volta à sua raça, para de novo reinar! (NASCIMENTO, 2004, p. 218 apud CARVALHO, 2015, p. 8).
\end{abstract}

No entanto, na adaptação, mesmo que as discussões sejam quase atemporais, decidimos trazer o cenário e a linguagem para os dias atuais. Nossa Jinga é uma mulher negra favelada, líder de sua comunidade, que, em uma guerra/tiroteio, encontra com Jasão, um homem branco e policial. Pensando que o "capitão" poderia oferecer-lhe uma vida economicamente melhor, Jinga deixa o morro da Costa d'Ouro, negando sua religião, as músicas, as vestimentas e até suas características físicas, quando tenta alisar o cabelo e alterar o modo de se vestir. Além disso, desfaz sua amizade com Ama, um homossexual negro, cabeleireiro, cozinheiro e que desempenha outras funções, pois, como diz em uma fala do espetáculo, "nessa guerra que a gente vive não dá pra dar mole não".

Depois de muito tempo, desde a última vez que Jinga e Ama organizaram um pagode juntas, as personagens se reencontram: Jinga agora se chama Medéa, é batizada na igreja evangélica e aparentemente está de volta "só para alisar, tingir e pranchar", visto que acontecerá um casamento de uma mulher branca - Creusa, filha do Sargento - no condomínio que mora com

\footnotetext{
${ }^{15}$ Estreia prevista para além dos muros da universidade em 2018.
} 
Jasão e os dois filhos, meninos brancos, que fora sua porta de entrada para o "mundo branco" ou "o outro lado" como as personagens tratam o bairro nobre onde moram as personagens brancas.

Como bem aponta Adélia Aparecida da Silva Carvalho (2015), no artigo "Além do rio - uma Medea na dramaturgia do teatro negro no Brasil", sobre dramaturgia negra a partir do texto de Agostinho Olavo, esse reencontro entre Jinga e Ama,

apesar de acontecer de forma trágica [...] simboliza a libertação da protagonista de uma escravidão psicológica à qual muitos negros estão sujeitos ao se deixarem acorrentar aos padrões impostos pelo ideal de branqueamento. (CARVALHO, 2015, p. 9)

É Ama que, nesse reencontro, atualiza Jinga da constante presença de militares na Costa d'Ouro, do genocídio cometido contra essa população, mas também das aprovações dos jovens do morro nos vestibulares das universidades públicas e da conquista de mais um dia sobreviverem, contrariando as estatísticas.

Depois que esses temas são colocados diante dos outros clientes do salão (público) e enquanto Ama no oficio de manicure canta os pagodes tocados no rádio, Jinga/Medéa se vê confortável para falar da sua relação com Jasão. Uma relação pautada na violência psíquica, sexual e física, tal como no texto de Agostinho Olavo e na história do Brasil: o contato forçado entre colonizador e a negra escravizada. Dessa forma, mesmo atenta aos acontecimentos "do outro lado", Ama sugere que Jinga/Medéa recorra ao jogo de búzios para confirmar suas intuições e suspeitas. E é nesse momento em que Jinga cumpre o ritual e expõe o motivo real da sua visita/retorno à Costa d'Ouro.

O espelho do salão da Ama é ressignificado e se torna o jogo de búzios, o oráculo. Esse reflexo, que tem referência no rio de Agostinho Olavo - água que batiza Medéa e tenta retirar as raízes da personagem - devolve em imagens o casamento do branco Jasão com a branca Creusa. A cena, a princípio, parece meramente desvelar a traição de um homem, o que não exclui a negatividade dessa situação. Porém, a escolha do espelho - o rio construído em Ama - anuncia o rompimento do elo erguido entre Jinga ao "mundo branco", "o outro lado" da imagem. Imagem/reflexo tão caros quando pensamos nos padrões estéticos e culturais impostos pela cultura branca/europeia/dominante/opressora.

Vendo-se à frente desse reflexo, Jinga veste o figurino da morte para de novo reinar. 


\begin{abstract}
Sabendo serem os filhos o último elo significante de sua ligação com uma situação que quer deslocar e romper, Medéa os encaminha para as águas. Prevendo que as crianças não sobreviverão à passagem. A morte dos filhos simboliza um sacrifício pessoal de Medéa e uma ruptura da rede de subordinação que a prendia. Seu gesto trágico é fruto de uma decisão pessoal, irreversível e inexorável. Como pharmakós, remédio e veneno, a morte dos filhos rompe, metafórica e literalmente, a prisão da mãe. Simultaneamente punindo Medéa e purificando Jinga (MARTINS, 1991, p. 138 apud CARVALHO, 2015, p. 16).
\end{abstract}

Mesmo diante do longo tempo-espaço entre Agostinho Olavo e Espaço Preto, Ama e Além do rio

nos permite[m] refletir sobre a proposta estética presente nessa dramaturgia de um Teatro Negro, através de uma inversão de valores no que diz respeito à temática, composição de personagens e linguagem construindo ainda uma relação com o ritual, musicalidade e estrutura cíclica tão presente na cultura negra (CARVALHO, 2015, p. 9).

O desafio de Ama é agir com profundidade nos questionamentos abertos por Agostinho Olavo sobre diversos temas. Assim, afirmando o papel principal que vem sendo desempenhado pela Cia Espaço Preto em ampliar as discussões estéticas, poéticas e artísticas na construção de um Teatro Negro.

\title{
5 CONSIDERAÇÕES FINAIS
}

Estamos indo para o quarto ano desde a criação da Cia. Espaço Preto e já participamos de festivais e mostras significativas que nos revelaram a importância de seguir com o projeto, como a Mostra Benjamin de Oliveira ${ }^{16}$ e a Mostra Marginal. Apresentamos em ambas $O$ grito do outro - $o$ grito meu!, espetáculo que, como exposto na sinopse, aborda o racismo e a construção das identidades em uma sociedade que se funda sobre o mito da democracia racial. A pesquisa, voltada para a dramaturgia negra e para a arte marginal, trabalhou com textos autorais e buscou elementos do hip hop, com foco na musicalidade e corporalidade. Em cena, indivíduos marginalizados usando da arte marginal para se colocarem como foco do discurso. Na equipe deste espetáculo, dividindo tarefas entre elenco, produção, plástica e técnica, estão todos e todas as integrantes que atualmente compõem a companhia: Ana Martins, Anair Patrícia, Andréa Rodrigues, Elisa Nunes, Guilherme Diniz, Michele Bernardino, Rainy Campos, Sitaram Custódio, Will Soares e eu.

\footnotetext{
${ }^{16}$ Fotos 1 e 2 em anexos.
} 
Em Belo Horizonte, não somos o primeiro ou o único grupo de teatro negro. Hoje, além dos projetos segundaPreta e Aquilombô ${ }^{17}$, resistimos juntos com a Cia. Burlantis, O Teatro Negro e Atitude, O grupo dos Dez, o Coletivo Negras Autoras e alguns artistas independentes como João das Neves, Adir Assunção, Gil Amâncio, Grace Passô, Zora Santos, Benjamin Abras, entre outros que tanto lutaram para nos "passar o bastão" e continuar a luta. Porém, é evidente que, depois das narrativas registradas sobre nosso processo de formação, estamos em um lugar singular na criação de uma poética periférica e urbana. Atravessamos o limite criado para se tratar da história e da vivência do negro no Brasil, por vezes relacionadas somente às religiosidades, ao propor uma dramaturgia que se atenta para as discussões mais especificas sobre a mulher negra e o genocídio de jovens negros. Esse diálogo fazemos com mais proximidade das companhias Os Crespos e Coletivo Negro, de São Paulo - SP.

Por fim, ou quase fim, coloco as experiências vividas e observadas na (e com a) Espaço Preto na bagagem. Experiências que me fortaleceram e geraram fôlego para continuar a luta/vida, pois, se ainda estamos construindo, reconstruindo e ressignificando a arte teatral, quer dizer que são longos os caminhos do Teatro Negro. Caminhamos na perspectiva de ampliar o repertório e em elaborar outras formas, outros temas, outras cores e texturas para encenarmos nossas histórias.

\section{REFERÊNCIAS}

ALEXANDRE, Marcos Antônio. O teatro negro em perspectiva: dramaturgia e cena negra no Brasil e em Cuba. Rio de Janeiro: Malê, 2017.

ATHIÊ, Joyce. No calor da cena. 2016. Disponível em: <http://galpaocinehorto.com.br/no-calor-dacena-15-09/>. Acesso em: 12 jul. 2018.

CARVALHO, Adelia Aparecida da Silva. Além do Rio: uma Medea na dramaturgia do teatro negro no Brasil. Urdimento, Florianópolis, v. 1, n. 24, p.06-27, jul. 2015. Disponível em: <http://www.revistas.udesc.br/index.php/urdimento/article/viewFile/1414573101242015006/447 4>. Acesso em: 12 jul. 2018.

GOMES, Nilma Lino. A mulher negra que vi de perto: o processo de construção da identidade racial de professoras negras. Belo Horizonte: Mazza Edições, 1995.

\footnotetext{
${ }^{17}$ Espaços de apresentações, diálogos e pesquisas produzidas por artistas negras e negros. Residências, resistências e aquilombamentos de Belo Horizonte que também recebem e inspiram movimentos e artistas de outras cidades do país.
} 
INSTITUTO DE PESQUISAS E ESTUDOS AFRO BRASILEIROS (Brasil). Abdias Nascimento. [201-] década certa. Disponível em: <http://ipeafro.org.br/personalidades/abdias-nascimento/>. Acesso em: 12 jul. 2018.

MARTINS, Leda Maria. A cena em sombras. São Paulo: Perspectiva, 1995.

MOURA, Christian Fernando dos Santos. Notas sobre a cena. Resenha ensaística. Belo Horizonte, 2014.

NASCIMENTO, Abdias. Dramas para negros e prólogo para brancos: antologia de teatro negrobrasileiro. Rio de Janeiro: Teatro Experimental do Negro, 1961.

PAVIS, Patrice. Dicionário de Teatro. Tradução de J. Guinsburg e Maria Lúcia Pereira. - 3. ed. São Paulo: Perspectiva, 2011.

SILVA, Andréa de Fátima Rodrigues. Entrevista concedida no bate-papo pós apresentação do espetáculo $O$ grito do outro - o grito meu!. Belo Horizonte: Companhia Espaço Preto, 2016.

SIMSON, Olga Rodrigues de Moraes. Visões singulares, conversas plurais. Textos de Olga Rodrigues de Moraes von Simson et.al. São Paulo: Itaú Cultural, 2007 (Rumos Educação Cultura e Arte, v.3). p. 13-38.

\section{ANEXOS}

Foto 1: Espetáculo “O grito do outro - o grito meu!” na IV Mostra Benjamin de Oliveira - Junho, 2016

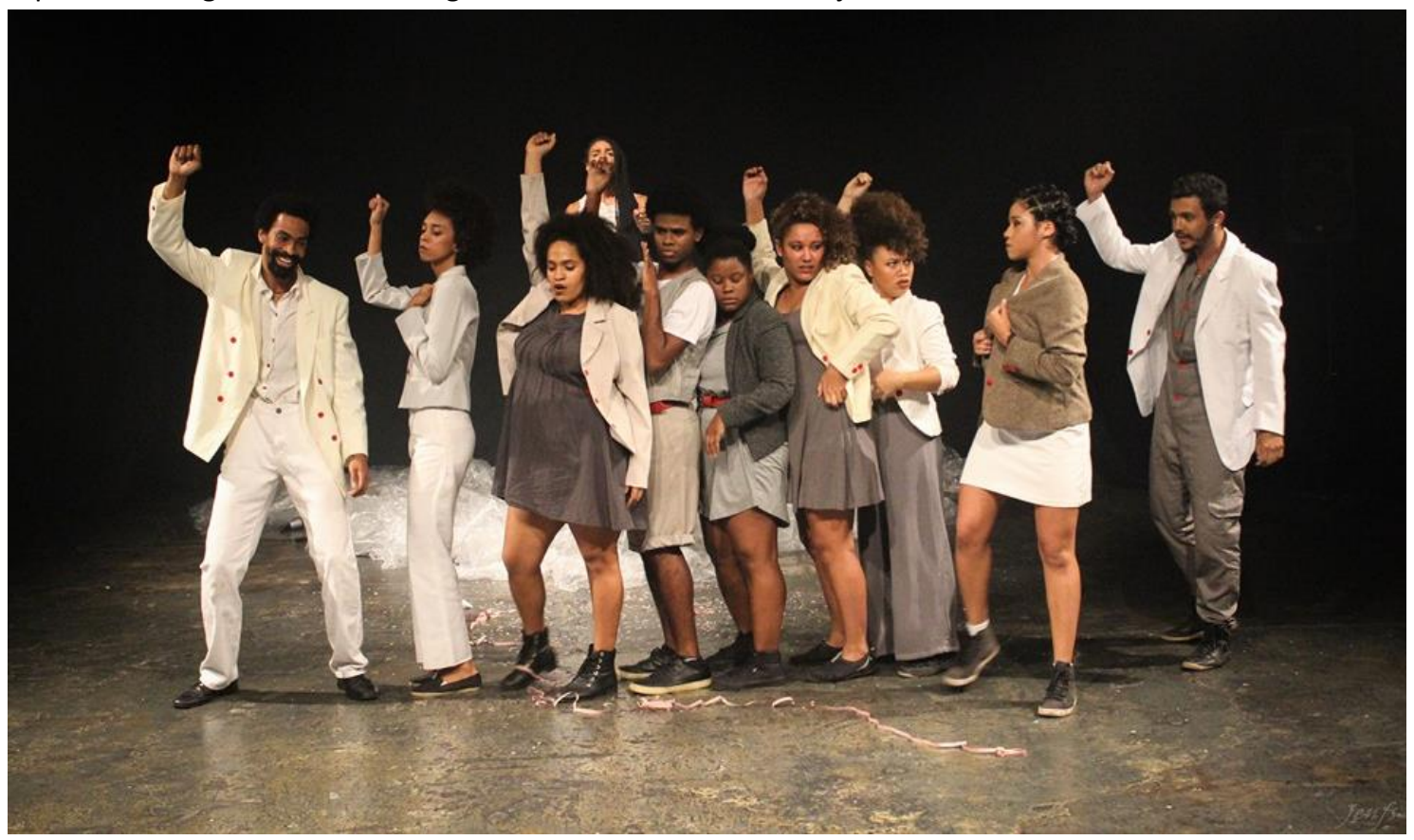

Foto; Jenfs Martins (2016) 
O teatro negro proposto pela Cia. Espaço Preto ou a formação de um ator-pesquisador-docente negro Anderson Ferreira do Nascimento

Foto 2: Espetáculo "O grito do outro - o grito meu!" na IV Mostra Benjamin de Oliveira - Junho, 2016

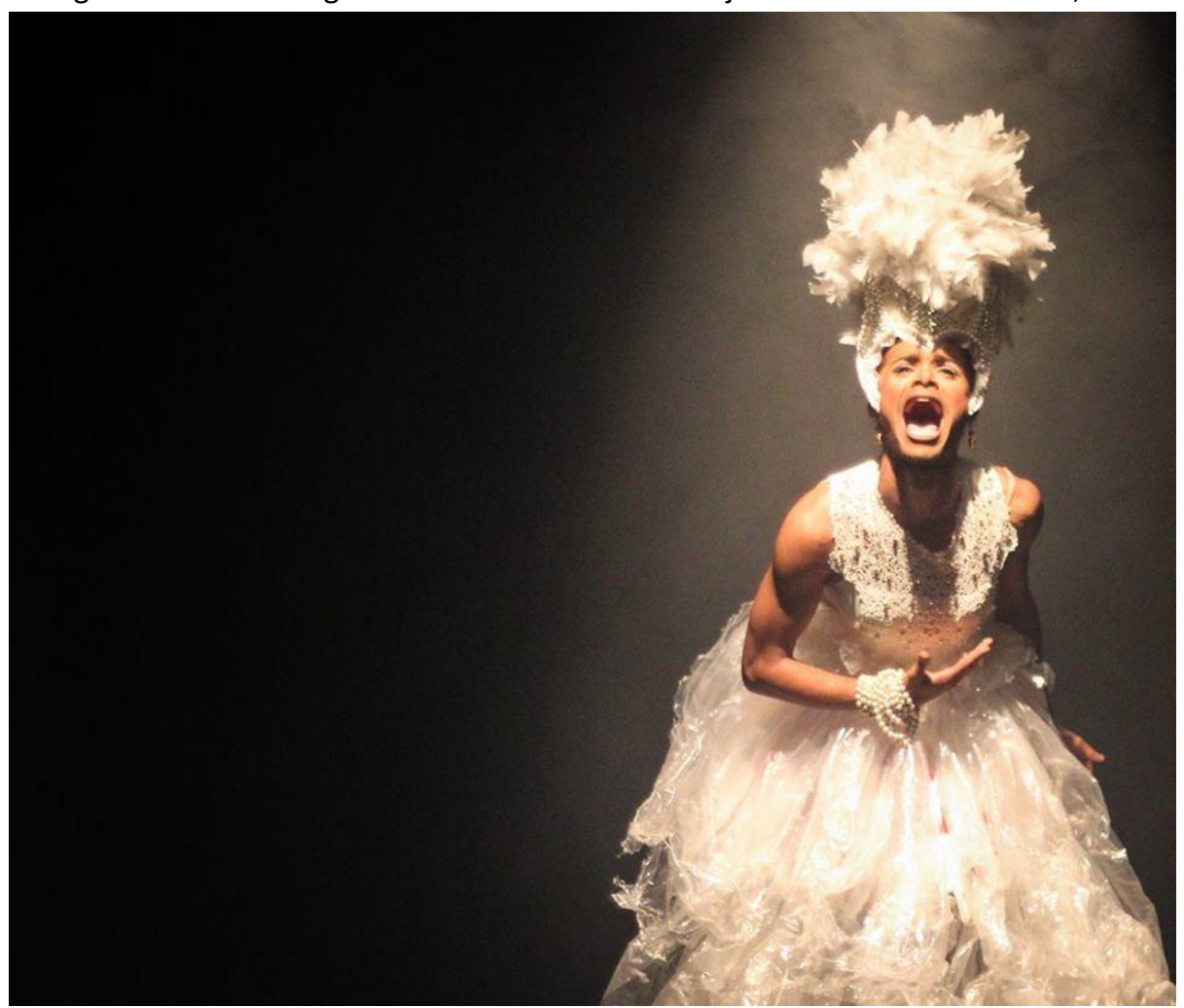

Foto: Jenfs Martins (2016)

Foto 3: Espetáculo "O grito do outro - o grito meu!" na Abertura da Amostra.Lab - Agosto, 2016

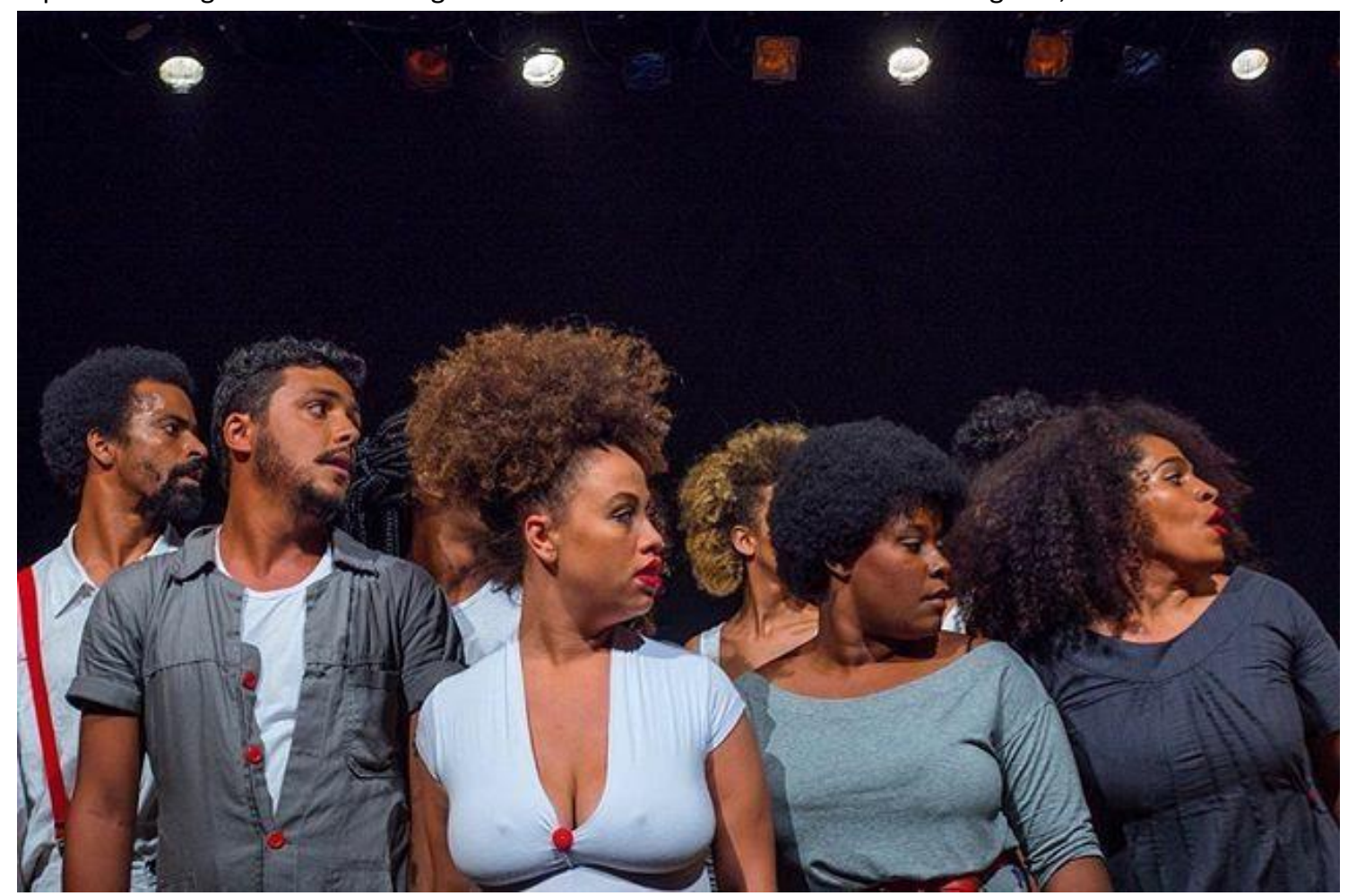

Foto: Ramon Brant/Dentro da Cena (2016) 
O teatro negro proposto pela Cia. Espaço Preto ou a formação de um ator-pesquisador-docente negro Anderson Ferreira do Nascimento

Foto 4: Cena curta “Ama” no 17ㅇ Festival de Cenas Curtas do Galpão Cine Horto - Setembro, 2016

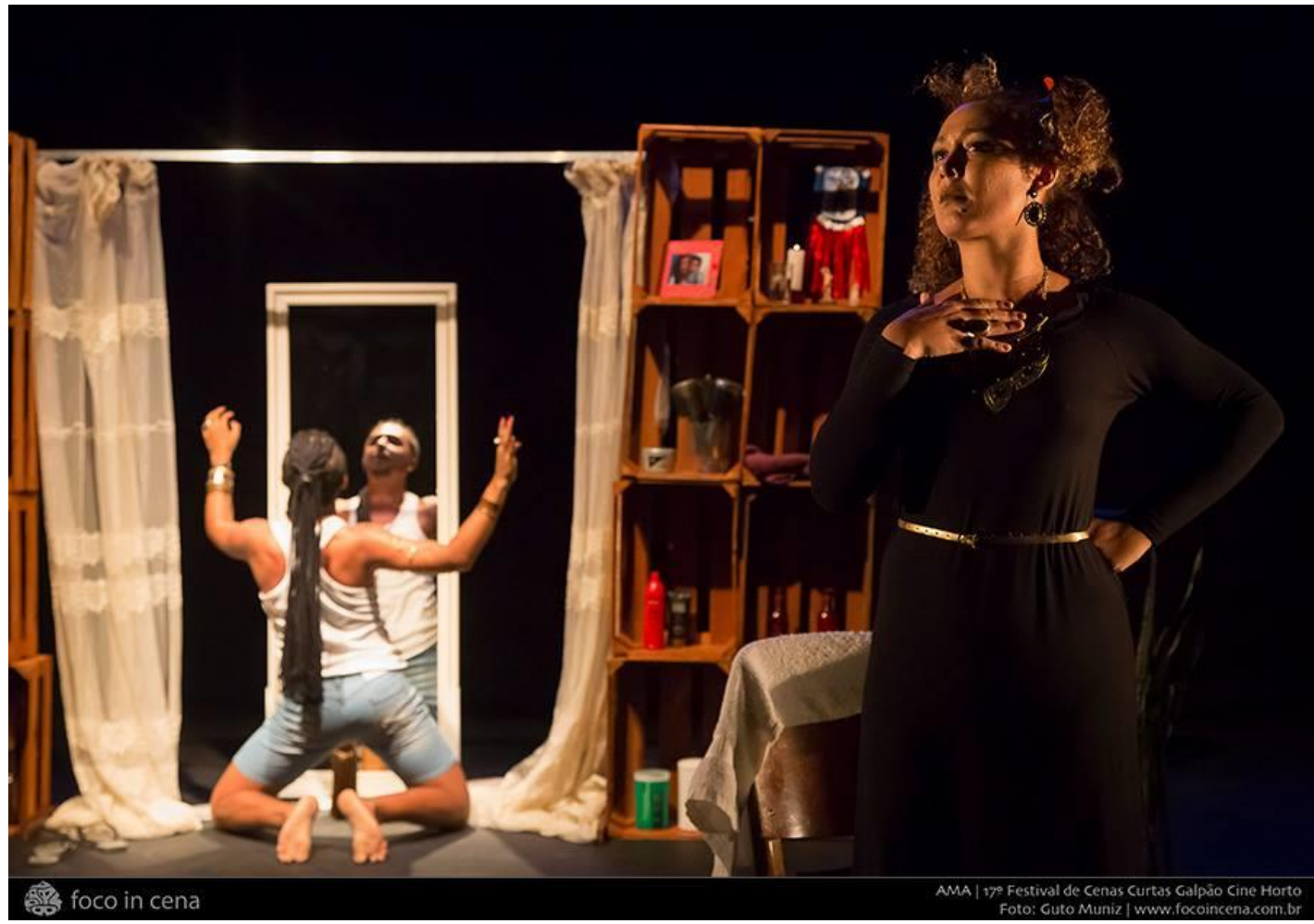

Foto: Guto Muniz (2016)

Foto 5: Espetáculo “Ama”, na apresentação para banca do Trabalho de Conclusão de Curso - Dezembro, 2017

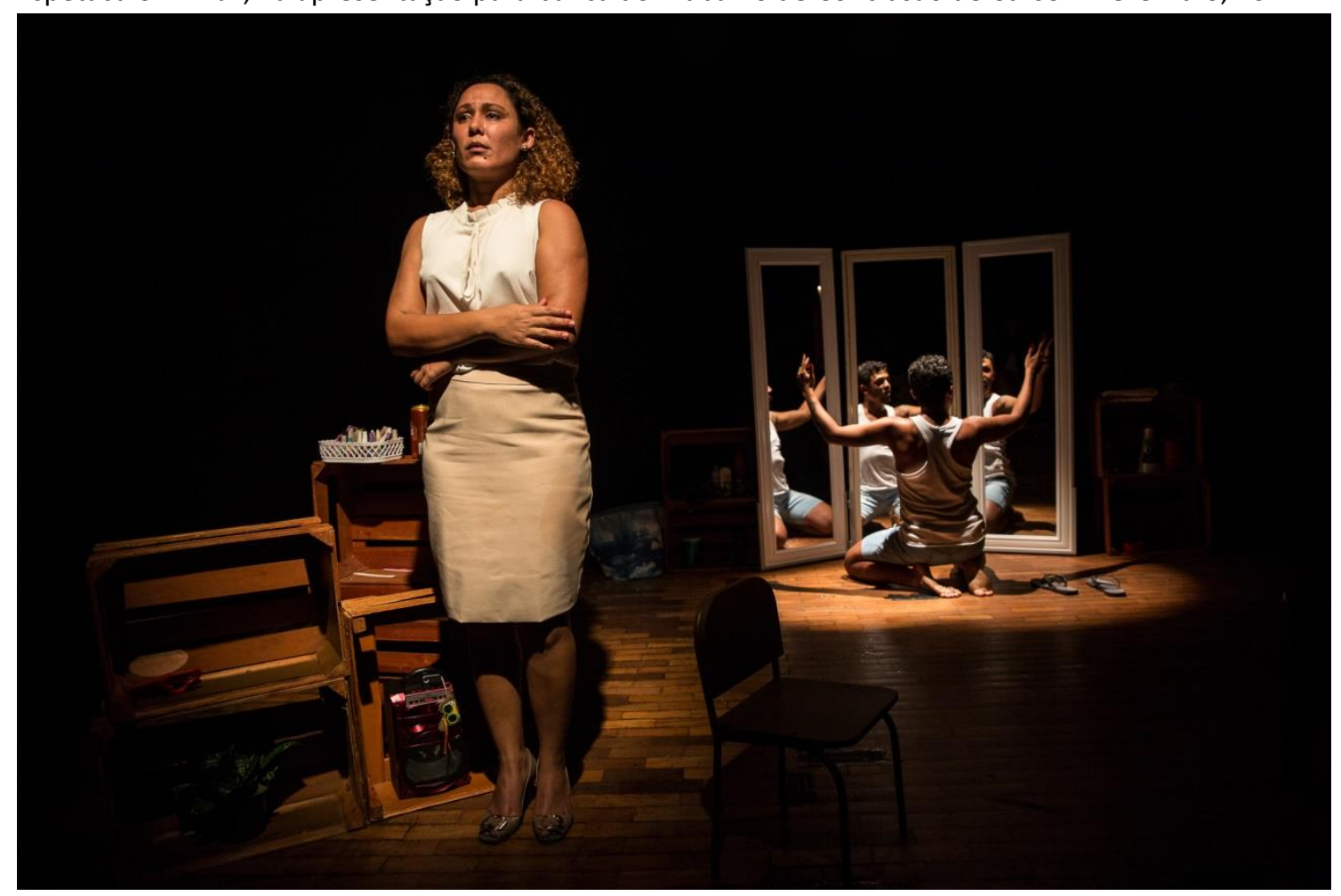

Foto: Pablo Bernardo (2017) 
O teatro negro proposto pela Cia. Espaço Preto ou a formação de um ator-pesquisador-docente negro Anderson Ferreira do Nascimento

Foto 6: Espetáculo "Ama”, na apresentação para banca do Trabalho de Conclusão de Curso - Dezembro, 2017

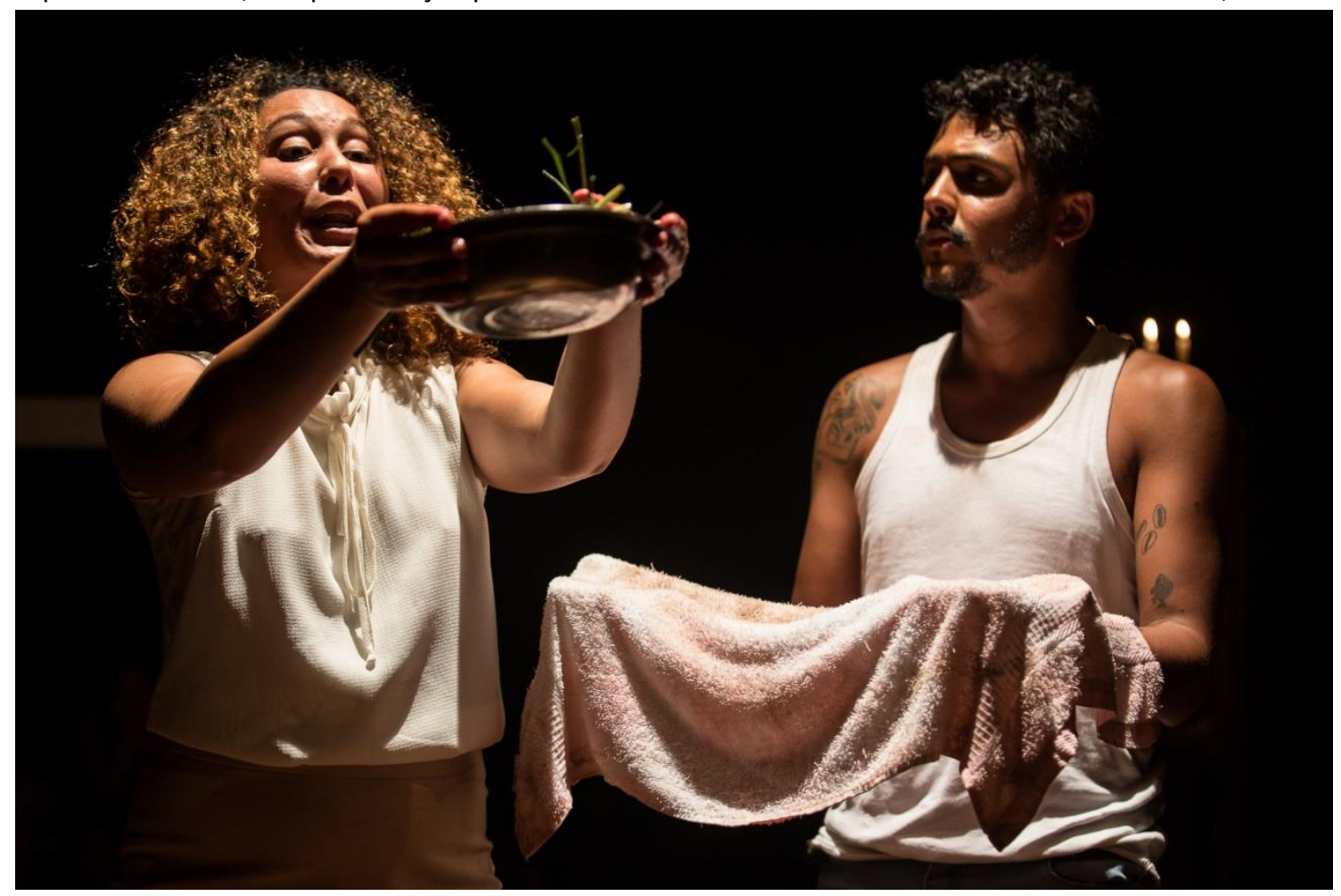

Foto: Pablo Bernardo (2017). 